\title{
Decolonial pedagogy through transcultural narrative inquiry in the contact zone
}

\author{
Hartej Gill \\ University of British Columbia \\ Hartej.gill@ubc.ca \\ Vincent White \\ University of British Columbia \\ vincentj@mail.ubc.ca
}

\begin{abstract}
Given the often tokenistic, ahistorical and apolitical approach to mainstream multiculturalism employed in schools, this paper theorizes transculturalism and decolonial thinking from a pedagogical perspective while also considering its potential as a transformative method of inquiry. Of particular interest to the authors is how employing transcultural narrative has the capacity to explore colonialism outside and beyond a conventional historical context in order to understand its impact on the present day. To this end, the authors discuss transcultural narrative as a form of decolonial pedagogy and inquiry, one that invites messy and often uncomfortable intro/trans-spective reflections where conflicting cultural, social and historical locations come into contact. This contact zone effectively compels unsettling dialogue between the colonizer/settler and the colonized, whiteness and color, privilege and marginalization, obstructionist and agency/ally work etc, locations which the authors argue are best understood collectively, relationally, and along a continuum rather than as a fixed binary. The authors present an example of this form of engagement (in the form of a transcultural narrative between an instructor and guest speaker), including the rationale through which it was actualized as well as some of the new inner/understandings that emerged from the inquiry experience. The potential to employ transcultural narrative as a pedagogical process of inquiry is also discussed.
\end{abstract}

\section{Transculturalism and the colonial matrix of power}

In an effort to disharmonize "multiculturalism," the term transculturalism (Mignolo, 2001) has received considerable attention in the area of Subaltern Studies over the last decade As part of this important work, Mignolo demands a move away from the concept of celebrating cultural diversity to raise awareness of colonial difference. In this manner, as Delgado and Romero (2001) highlight, Mignolo's transculturalism is always performed in power structures between hegemony and subalternity. Such decolonial thinking (Tlostanova \& Mignolo, 2012) recognizes not just colonialism, but rather a "colonial matrix of power" (p. 18) as part of the existing global design and world order. Mignolo critiques the conventional use of the term "colonialism" that distantly and comfortably situates it within a historical context. Conversely, he draws our attention to the concept of "coloniality," one that is consistent with the Peruvian liberation theologist, Anibal Quijano's notion of the "coloniality of power". This compels an understanding

Cultural and Pedagogical Inquiry, 2013, 5(2), pp. 25-38

ISSN 1916-3460 @ 2013 University of Alberta

http://ejournals.library.ualberta.ca/index.php/cpi/index 
that "coloniality is constitutive of modernity and as a consequence, we are still living under the same regime" (Mignolo, 2001, p. 71). Tlostanova and Mignolo, (2012) highlight modernity as the rhetoric of forced universal salvation and the naturalization of Western epistemic privilege.

Coloniality and decolonial thinking are essential concepts that are missing from the often tokenistic, apolitical and ahistorical approach to mainstream multiculturalism ${ }^{1}$ in schools. The "colonial matrix of power" (Tlostanova \& Mignolo, 2012) resiliently constituted by Eurocentrism, modernity, capitalism and colonialism continues to dominate institutional knowledge curriculum and pedagogy in ways that purposefully obstruct meaningful classroom conversations about history, equity and justice. However, it is well worth noting that writing in this area has significantly emerged in the field of Latin American Subaltern Studies where many of these issues are theorized conceptually in isolation of lived discursive contexts. In our view this non-contextual focus has the potential to perpetuate a privileged notion of ambiguous concepts that require multiple "innerstandings" of diverse epistemologies and ontologies.

\section{Conceptualizing a transcultural narrative}

In an effort to build on and extend this important work, this paper discusses transculturalism and decolonial thinking from a pedagogical perspective and as a potential method of inquiry. In this work, we demonstrate that transcultural narratives can be effectively employed as a form of decolonial pedagogy. This manner of engagement has the potential to uncover and raise awareness of the messy spaces where conflicting historical, social and institutional locations come into contact when relational narratives are invited/compelled between those that represent the continuum between the colonizer/settler and the colonized, whiteness and color, privilege and marginalization, obstructionist and ally.

The conventional approach to exploring social justice for example includes traditional academic writing, presentations and panels involving the sharing of individual papers and writings that are typically followed by discussions and question sessions - often again for individual panelists. This approach works well for many areas of academia. However, we argue that when we engage in transcultural spaces in the contact zone, a more colocative process is necessary; one that has the potential to uncover how power, history and inequities intersect and are situated within larger societal systems of oppression and marginalization. This transcultural narrative is proposed as an important pedagogical

\footnotetext{
${ }^{1}$ We recognize that many important critical approaches to multiculturalism have been developed by scholars and this paper does not intend to minimize this research. Our critique here is of more liberal and mainstream notions of multiculturalism which are unfortunately prevelant in educational settings and society. It must be recognized that the significant works of Ali Abdi, James Banks, George Sefa Dei, Carl Grant, Ratna Ghosh, Reva Joshee, Will Kymlicka, Gloria Ladson-Billings, Sonia Nieto, Christine Sleeter, Patrick Solomon, Handel Wright, and many others certainly disrupts this work through critical, anti-racist, anti-colonial educational and policy frameworks.
} 
strategy and inquiry process for understanding intersectional and co-intersectional epistemologies and ontologies in the contact zone - a zone where the "colonial matrix of power" cannot be ignored.

\section{Inviting/compelling the transcultural narrative}

Essential to this form of engagement is the willingness of two or more individuals to reflect on their own social and institutional locations in ways that allow them to identify how their identities intersect and what are the implications of those intersections in the 'contact zone.' Critical to this process is an understanding of these locations of conflict as existing along a continuum rather than belonging to a fixed binary. For example, a participant may be invited ${ }^{2}$ to consider in what ways they self-identify as representing for example a colonizer/settler or colonized, whiteness or colour, privilege or marginalization. This, in essence, begins the dialogue, which as a narrative, takes the form of telling one's story in relation to this identity. The juxtaposition of two or more stories representing positions in the contact zone has the capacity to transform the story into a decolonizing relational narrative. This narrative, in turn, has a transformative potential on the participants' story, or at least in terms of how that story is understood from a transcultural perspective. The process itself is deeply embedded in the notion of decolonizing the relational hierarchies in ways that make explicit hegemonic forces. In this sense, the intention is not to neutralize the relational hierarchies to some point of resolution, but to instead surface discomfort, uncertainty and greater awareness of the relational intersectionality and co-location within a colonial matrix of power in the current world order. Participants (those living the complex opposing realities) have the potential to be unsettled by the decolonizing transcultural narrative and inquiry process in ways that have the potential to bring about new inner/understandings.

\section{Authors' reflections on the process of engagement}

We were compelled to engage in a Transcultural Narrative in order to find a creative and embodied way of bringing difficult social justice issues into the classroom setting. Given the resistance that can often emerge in educational settings (especially for racialized instructors) when issues of colonialism for example are surfaced, we were attempting to find a proactive pedagogy to discuss issues that are crucial to education yet often absent from Eurocentric schooling. Sharing a transcultural narrative, we felt would allow us to present multiple yet hierarchical perspectives and locations in a way that would allow participants to make greater connections and resonances to their experiences while at the same time allow some of those experiences to be validated. In fact, the idea of the Transcultural Narrative emerged out of a discussion about one instructor's deep concern

\footnotetext{
${ }^{2}$ We recognize that these messy, complicated and often oppressive conversations take place on a daily basis in all social, educational and political settings. This paper highlights the space when they may be brought in intentionally for pedagogical purposes into educational spaces (where again they already exist, but often can get ignored, minimized or are only tokenistically addressed).
} 
for not wanting to expose a guest speaker to the backlash that he thought might take place given some of the individuals in this particular setting.

Instructor: The first sense I had of the guest speaker is that she had a compelling life story to tell, and that this was an essential part of her work. I really didn't see how my own story or way of being in the world had any connection to it. I was becoming more aware of my responsibilities in relation to social justice, but very little of this involved any consideration of my own location as a White settler in this society.

Guest speaker: The instructor seemed like the right person to engage with in a relational narrative of this nature. He appeared genuine in his intentions to bring issues of social justice into his university teaching. He had, in fact, been hired as a sessional instructor for a diversity cohort program in the university's pre-service teaching program. He also seemed to be quite introspective about his own lived experiences, but I didn't get a sense that there was any self-awareness of how he was implicated in colonialism.

As the transcultural narrative emerged the intersectionalities of marginalized and privileged social and institutional identities and their rootedness in colonialism and coloniality could not be ignored.

Instructor: As an undergraduate, I concentrated a lot of my studies on European History, and so the guest speaker's notion of coloniality immediately conjured a historical context. Initially her questions and contributions led me to wonder if the intention of our transcultural narrative would compel me to consider my ancestors and what role they may have played in historical injustices or how they may have been impacted by historical injustices as part of Irish, Scottish communities living in extreme poverty. It took a while for me to realize that she was also gently pushing me to explore my own story and to what extent it reflected the experience of being white and privileged in Canada. Admittedly, this constituted a bit of a paradigm shift, one that provoked in me a range of reactions including some defensiveness.

Guest speaker: Although, it was challenging, I really believed that if we allowed for a "genuine letting go of our discomfort" the process of engaging this transcultural narrative would enable us to critically look at issues of: whiteness/color, settler, citizen, and historical contexts of Canadian nation building, coloniality, subaltern knowledges, border thinking, belonging, home, voice, responsibility and resistance, in pedagogically meaningful ways.

Instructor: Initially, I got caught up in the pragmatics of the whole thing. How were we going to build a story that somehow combined the lived experiences of a woman born in India who moved to Vancouver as a child, with that of a white guy who was born and raised in Toronto and then moved to Vancouver? I didn't really see any connections between these two journeys, but was very much intrigued to see what would unfold from this process. 
Guest speaker: There were points in our story where I now realize that I really wanted the instructor to embody the colonizer and understand how he was implicated in the colonial history of Multicultural Canada (as complicated as his own story was) in more a explicit way than he was comfortable. I needed him to take on the colonial/settler mindset in a sense so that I could counter this with the reality of my own lived experiences. You could tell that he was wrestling with this, saying to himself: "But that's not me. And then I remember a point in time, where he shifted to a new understanding that was... "Well, I guess to some extent that is me, because I'm a part of this and don't really do anything to change it." I also wrestled with this. Was I imposing this on him? Was I expecting him to 'take the fall' for some of my lived experiences? Was I aware of my own privilege despite my color and the daily and systemic racism? Was I even aware myself of whose land I was living on - my settler identity as a racialized woman?

Instructor: We would get into these disagreements about whether anything good had come out of multiculturalism. I'll admit that initially I had a hard time with the guest speaker's indictment of it as a colonial discourse. It represented one of the core ideals of what I thought Canada and Canadians deserved to be proud of. I still have a hard time with this. The interesting thing that we began to realize is that the transcultural narrative gave us a vehicle to move beyond disagreement and back to our story and the emergent co-learnings.

\section{Our transcultural narrative}

Guest speaker: My parents breathe in the last of India. The house is emptied of all life and belongings. All that is left is what hangs from the ceilings -- the Komagata Maru men, their blood dripping on the bare white walls. From the kotas can be heard cries and laments. Relentless pain. Stories long forgotten or unheard in other lands will echo eternally in this village, even when it is abandoned. Stories abandoned for other stories. From rags-to-riches-stories. Snow-White-Cinderella-stories.

My parents try to erase the painful past from their memory as they prepare to betray their country, their home, their HIStory, their ancestors. Instead, they try to redeem themselves. They speak of the family they helped during the Partition. In sorrow, they wonder if the Muslim family who buried their jewels in our bara will ever come back to find them. Did they even survive? Did they make it over the b/order? Forced out of a country we are leaving by choice. My parents pray that if they return, they will find their riches by the Saron tree where they left them.

Suitcases in hand they close the door slowly and sadly with a silent prayer. We walk down the long stairway in the darkness of the late evening. As we arrive at the bottom step we see for the last time the family who sleeps there under our awning. The husband, his wife and child, who beg throughout the streets of the village by day, always return here by night. This is their home -- their imposed home. The home we are leaving is the home they return to. The one they are compelled to be committed to.

We walk over them, as we have become accustomed to doing. But this time is different than all the other times that we have walked over their bodies. This time as we walk over their bodies, we are walking over all the bodies of our ancestors. 
Their ashes are here in this earth.

Nurturing us with a constant reminder of their resistance and their despair.

The rice of this land still grows with traces of a colonizer's skin.

This time as we walk over their bodies we are pained by a sense of selfish forgetfulness and shameful regret. As we walk away we know they are watching, but if we do not look back, perhaps they may never see the treason written on our betraying bodies.

From the golden domes of Delhi, our plane flies into the silvery sky and I am home away from home always searching for my home.

Instructor: "Forgive us our trespasses as we forgive those who trespass against us"

Guest speaker: Standing behind the chair attached to the pale brown desk, I obediently repeated these words from the Christian Bible as part of the daily activities of my Grade Two year in Vancouver, B.C. Canada. When I sat down I dutifully printed the prayer on the brown paper provided. Etching each sacred word carefully. Not knowing anything about colonial histories, coloniality, dispossession, genocides or epistemic violence, I wondered what these words meant.

Instructor: In my family, these were words of a Sunday morning ritual. Standing together at mass reciting the Lord's Prayer, I would frequently glance over at my father and study the pious image that would emerge each Sunday. A morning that too often followed a night filled with alcohol and rage. For some reason, it seemed evident early on in my life that both of these 'traditions' had carried on in my family for generations. However, it wasn't until much later in life that I wondered to what extent working class forces connected to the colonial nature of the famine had influenced both of these rituals.

Guest speaker: Identities (colon): ESL student, non-speaker-(no language) nonCanadian, naturalized Canadian..not immigrant..." Imposed colonial identities by the "pure" on the "impure".

Arbitrary words of an arbitrary agenda.

Teaching in front of the class, Mrs. Wilson clearly informed us that marriage between different races would result in deformed, mutilated monster babies. Whites should only be with Whites - this is the master race, the pure race. The colonial borders were clearly drawn geographically, politically, economically, relationally even in grade 2 ...

Instructor: From somewhere within my family I remember being gently encouraged early on in my childhood to not mix race. It was always accompanied with a wellintended gesture that clarified that we had "nothing against coloured people". It was just a general understanding that a "mixed race" offspring was something to be avoided. I never dug underneath the surface of this, and it seems curious to me now that I can't distinctly locate who is primarily responsible for promoting this sentiment. It just seemed to somehow become part of a family consciousness and actually the norms of society in my upbringing at that time.

Instructor and Guest speaker: Amen 
Guest speaker: I place my hand on THE Bible and swear my allegiance to Canada And to the Queen.

To Canadian Citizenship, And to bodily silence.

And I belong in an unbelonging-belongingness.

In "Multiculturalism" Canada, we do not talk about racism or colonialism. But in times of social, political, and economic unrest and in times of crisis and especially in times of terrorism, we talk about immigration and we talk about citizenship. Citizenship in Canada is about ambiguous borders and invisible boundaries. It is about entitlement, it is about acceptance, and it is about silence and silencings. Through this colonial discourse, the colonial past is in the past -- in history.

New exclusionary immigration laws along with increased "Multicultural" education are the paradoxical answers that supposedly give ALL "Canadians" the assurance that EVERYONE will be "safe" on these colonized lands.

I present my passport

Instructor: My citizenship...

Guest speaker: My Canadianess..

Instructor: I am Canadian!

Obviously I am Canadian, or so I remember being told by a Canadian Border Services agent in Seoul when I had lost my passport and was stranded.

"If it were up to me," he said, "I'd let you go home today, But "They" (gesturing to the Korean officials) won't accept my word for it."

It wasn't until years later that I reflected on this experience and wondered what was it about me that made the Canadian agent so certain of my Canadian-ness. I obviously represented what he was used to seeing as Canadian, but what was the larger picture? Would others be afforded this same certainty by him or other agents... or was it more a matter of how well my/all Whiteness travels and has always travelled in history.

Instructor to Guest speaker: "But where are you really from?"

Guest speaker: Unconvinced they search the Indianness of my body. Turning it upside down, inside out. Emptying it, stripping it, forcing it open.

Even the inside is brown" they say

Immediately one is set apart from the norm and placed at the margins. One is either "Canadian" or one is not. It is assumed that cultural identity is rooted in the soil of one's birthplace.

Instructor: Are you Canadian? 
Guest speaker: Alien (definition) n.- syn. Different, dissimilar, outlandish, queer, outsider, barbarian, man without a country.

Instructor: Claims of a Multicultural Country and of a multicultural educational...

Guest speaker (coldly): ... Institution

Instructor: Claims of...

Guest speaker (mockingly): ..."Tolerance”

Instructor:...for

Guest speaker (pointedly):..."others"

Instructor (pleading):... And of social justice. Claims of meeting every child's needs.

Guest speaker (frustrated):...Piles and piles of paperwork claims dominated by the Dominant curriculum and the Dominant language, rather than the wild language

Instructor (correcting):... The bilingual,

Guest speaker (glares at Instructor)

Instructor (modifies): ...trilingual

Guest speaker (finally taking over): ... savage semi-lingual language. In a third space where multiple languages, multiple codes, multiple voices are invited and accepted as legitimate ways of expressing one's identities.

I am language. Until I can take pride in my language. I cannot take pride in myself. (Anzaldua, 1987, p. 59)

Instructor: I can recall an occasion a couple of years back when I got caught up in a debate about multiculturalism. I remember taking a strong position that multiculturalism, at least as I perceived it, had less to do with addressing the wrongs of the past and should instead be focused on the future. At the time, I even regarded myself as someone with the potential to play a leadership role in healing the divisions that existed within society through helping people 'move on' and let go of the past. There was a part of me that wanted to be instrumental in helping the world to finally get over it. To put the past in perspective and recognize that in the end... maybe we weren't really that different from one another.

Guest speaker: Why is my body suspicious of this well meaning, but privileged discourse often heard in the dominant society where there is lack of understanding of how our collective colonial past is our collective colonial present. I feel that we have gone from colonialism to post-colonialism without considering the space in-between - the decolonizing space, the decolonial space, the activist, healing space. Why has this process 
been overlooked? Whose interest would such a process serve or not serve?

As I speak, I am sensitive that my audience may be "like" and "unlike" me and may not completely understand or may not even hear or want to hear my words. Words of betrayal and disloyalty are difficult words to hear. They uncover, offend, hurt, cause discomfort. Even more so when they are honest, naked without metaphors as masks to hide the lies and to protect the Truths.

Social Justice and equity are not about saving us or telling us to forget the past, they are about addressing, acknowledging, and talking responsibility for the violence and exploitation of the past (even in Multicultural Canada). For the centuries of slavery, dispossession, and for decades of genocide, residential schools, eugenics, homophobia-for erasure, oppression, colonization, exploitation, capitalism, imperialism. It is not about silence and complicity and just "getting on with it." It is about challenging hegemonic/dominant knowledge and forces, by complicating pedagogy, by speaking out and by encouraging dangerous discourses. It is about healing, destabilization, transformation....

Instructor: White (definition) noun.. Colorless - syn. Clear, transparent, clean, blank, spotless, pure, unalloyed, neutral..."

Guest speaker: Dark (definition) adjective.. With little or no light...gloomy, dismal, evil, sinister, sullen, angry, secret, mysterious, ignorant, unenlightened, lack of knowledge

\section{Pause}

Instructor: Suddenly I feel quite uncomfortable with my whiteness. It's the privileged part that's awakening me to this discomfort. Not just history and its legacy, but how power is situated in today's world in ways that yield benefits for me that I readily accept at the cost of others. This new awareness is disturbing when I consider past intentions to help others 'get over it and move on.'

It compels me to stop talking and start listening.

To interrogate the place from which I approach the lived realities of racism, classism, sexism, heterosexism, ableism, colonialism, and coloniality.

To resist an inclination to try and fix something without having even taken the time to try and understand how these attempts to fix something may be perceived by others who have suffered injustices that are connected to my privilege.

What role, if any, do I have in a healing discussion? Why would anyone invite me in the first place if my stated purpose is to get people to move on and get over it.

I'm learning to lead by not leading and to speak by not speaking...

And yet to not remain silent in the face of continued acts of injustice.

I am learning to become an ally...I'm learning to become uncomfortable. 
Guest speaker: You must know that your whiteness is deceiving. A deep awareness lives in your soul -- perhaps they are the voices and memories of your elders and ancestors.

I am also a woman of privilege in terms of my "cultural and social capital" of education and language...Working in the academy, I can no longer come out pure. I'm not sure anyone can.

Not even my dear grandmother. Although she has come to live with the reality of her grand-daughter's British husband, she desperately hopes that none of her other grandchildren (especially the educated ones) will marry a Black person or a person with a disability or especially not turn out to be gay or lesbian. Like so many in our society (whether one is willing to admit it or not) she has been colonized multi-generationally over 500 years of colonization to believe that blackness, disability, queer identities represent the undesirables of society - those detrimental to progress and civilization and any association with them will lower one's status and truncate one's educational merit. As her grand-daughter, knowing that she only has the best intentions for me-for my upliftment from marginalization, how do I negotiate with integrity my beliefs in social justice and equity and her cognitive colonization (Battiste, 2000)?

Instructor: My new awakening brings with it a heightened awareness of how coloniality is situated globally in powerfully destructive ways. Suddenly, I'm painfully attuned to language and its susceptibility to these global forces and their impact on the multiple languages and cultures that give shape and meaning to the world around us. I'm reminded of what Wade Davis (2007) and others have described as the "ethnosphere" and its current state of rapid depletion. A gaping colonial wound left by the disappearance of half the worlds languages in recent history, and along with it, a cognitive consciousness of immeasurable diversity, which represents the only true way of understanding our world and its creator.

Guest speaker: "Cognitive imperialism denies people their language and cultural integrity by maintaining the legitimacy of only one language, one culture and one frame of reference. Cognitive imperialism is a form of cognitive manipulation used to disclaim other knowledge bases and values. Validated through one's knowledge base and empowered through public education. It has been the means by which whole groups of people have been denied existence. And have had their wealth confiscated (Battiste, 2000).

Instructor: I am learning to become an ally...I'm learning to become uncomfortable.

Guest speaker: Recently my family had a large holiday gathering at my parents' home. There was a very particular moment that comes to mind. There were about twenty people- family and friends- gathered in the living room when all of a sudden, during a silent moment I realized the potential for everything to go so wrong, and I somehow felt most responsible if it did, since I felt as if I was the only host (because of my location at the borders of cultures and classes) who "should have known better". At this gathering, there were many people of diverse backgrounds and generations present. My immediate 
family coming from a strong heritage of freedom fighters from India, my younger sister's very traditional British in-laws and their family. My sister's sister-in-law and her husband of Chinese-Canadian origin (these are all my simplistic categories, I'm not sure how these individuals would identify themselves.) and some family friends of various castes, classes and religions (including a Muslim family and a very devout Catholic family). There was also my colleague who was aboriginal who was asked to bless our meal before we shared it together. We had everyone from my parents who work in factories to university professors with quite a range in between (in terms of the traditional social hierarchy of society). There was also a close friend of mine that most of the family had not met. This woman was born with a degenerative disease and is now in a wheelchair permanently. I remember looking around and feeling a certain "transcultural discomfort."

First I hoped that no one would ask why my friend was in a wheelchair. And then I hoped that the topic of Christmas would not come up because there were so many conflicting views on it from various religious and cultural perspectives. And then I hoped that my younger cousins would not make any politically incorrect jokes that I would be put in a place to respond to in front of everyone. And then there were four generational sensitivities to consider, and various language barriers to deal with between my parents and my sister's British in-laws. And then, of course, I hoped that no one would ask about my research, because then colonialism would surely be discussed, and I would find myself right in the middle of everything trying to negotiate and find some "transcultural space of comfort" for everyone.

As you can imagine, it was a very exhausting evening.

I wondered after that evening about all the transcultural theories and transculturalism. I wondered if the people writing them really knew what it meant to live transculturally. If they had ever felt transcultural tension in the embodied and deeply emotional ways that I/we describe in our collective narrative. For if they had, I'm not so sure that their theoretical maps would be so concise, clean, clear....

\section{Pedagogical possibilities of transcultural narrative inquiry}

The compelling purpose behind this form of engagement is to extend discussions related to injustice and colonialism beyond the conventional disengaged format that not only falls short of understanding systemic and institutional oppression, but also minimizes lived injustices as collective stories impacted by the colonial matrix of power to individual experience of unfortunate and pitiful "circumstances", or worse "laziness" of the 'other'. We believe that engagement through transcultural narrative as a form of inquiry has the pedagogical potential to raise awareness of the collective and intersecting nature of these violent societal stories and to create an embodied inner/understanding of hierarchal intersectional realities rooted in histories of colonization and oppression.

Although the transcultural narrative shared above was initially written as a pedagogical strategy to share with a class in order to raise greater awareness of silent and silenced issues and perspectives, it became an incredible learning and inquiry experience for the 
authors even before it was shared with others in a classroom setting. It must also be noted that the story was not as linear, clean and concise as it is presented in the written text.

The pedagogical moments of our clashings in our transcultural narrative unearthed hierarchies and discomfort that disharmonized many eurocentric metanarratives of the hegemony of Whiteness, cognitive colonialism, civilizing missions of histories and legacies of colonialism and nation-building. It also allowed us to begin to understand the intersection of the colonizations of our ancestors. Through our engagement, we also became more aware of the sacredness of the space of the transcultural narrative and the importance of humility in discussions across difference where the smallest gestures and words needed to be acknowledged and validated as significant contributions to each others learnings. Further, we realized that allowing and pushing oneself to the places of discomfort is challenging work, but within a safe transcultural space, it is also crucial work. Constant reflection/self-reflection and learning/unlearning as part of this relational work is of the utmost importance in order to not offend, hurt or shame. Although, the possibility always exists that one will offend (unintentionally) and one must live with the awareness that "things will mess up", it is only from those messy moments that incredible transformation has the potential to emerge.

\section{Concluding reflections}

Genuine decolonizing transcultural narratives are emotionally difficult even more so in educational settings because of the added layer of the student-educator power dynamic. Further, it is not surprising to us as educators that present day euro-centric schooling does not provide spaces for students or teachers to engage in such dialogues (at least not comfortably) or to deconstruct and become aware of the eurocentricism and colonialism that they participate in and reproduce on a daily basis. Although there have been educational movements to bring non-eurocentric texts into the curriculum and teach the histories of "others" as a way of encouraging greater respect for difference, we would argue that these kinds of tokenistic and "othering" add-ons are simply not enough and often further perpetuate marginalization and oppression. Similarly, we would argue that parading stories of trauma of "others" without critical engagement in the issues involved or simply sharing about experiences of racism, sexism, ableism, classism, antiheterosexism, colonialism without an intersectional engagement or historical analysis is also counter-productive to social justice educational goals of raising awareness and changing consciousness. Instead we propose embodied transcultural narratives (whether prewritten as for this class or through thoughtfully planned and facilitated relational dialogues) as part of an integrated pedagogy of decoloniality in order to raise awareness across colonial difference (rather than cultural difference). Through this approach one can no longer articulate social and institutional locations in isolation of "others" but must learn to reach across the racial, social, institutional and colonial divide to collectively come to historical and intersectional understandings of difference. This kind of decolonial pedagogy and inquiry process we hope will be the starting point for complicated conversations and dangerous discourses toward a greater innerstanding of the messyness of the colonial divide and the colonial matrix of power. 
We would like to acknowledge the traditional, unceded and ancestoral terroritory of the Musqueam People where the University of British Columbia is located and where this work orginates.

We would also like to acknowledge and honour our elders and ancestors for their struggles with racism, classism and colonialism that guide the work that we do in academia.

And finally, we would also like to acknowledge the significant work of Kadi Purri whose research in a shared Ph.D. chapter with Hartej Gill, was an important beginning to the importance of engaging transculturally. 


\section{References}

Anzaldua, G. (1987). Borderlands/la frontera: The new mestiza. San Francisco: Aunt Lute Book Company.

Battiste, M. (2000). Reclaiming Indigenous voice and vision. Vancouver, BC: UBC Press.

Davis, W. (2007). Light at the edge of the world: A journey through the realm of vanishing cultures. Vancouver, B.C.: Douglas and MacIntyre Ltd.

Delgado, E. \& Romero, R.H. (2001). Local histories and global designs: An Interview with Walter Mignolo. Discourse, 22 /3, 7-33.

Gill, H. (2003). Im-person-ating identity in spaces of difference. Unpublished Ph.D. Dissertation, University of British Columbia, Vancouver, British Columbia, Canada.

Mignolo, W. D. (2001). Local histories/global design: Geohistorical spaces and epistomological locations. In P. Lange and E. Mendieta (Eds.). Latin American Post-Modernity: A contemporary reader (pp. 177-208). New York: Amherst Books.

Purru, K. (2003). Acknowledging home(s) and belonging(s): Borderwriting, Unpublished $\mathrm{Ph}$.D. dissertation, University of British Columbia, Vancouver, Canada.

Smith, L. T. (1999). Decolonizing methodologies: Research and Indigenous peoples. London: Zed Books Ltd.

Tlostanova, M.V. \& Mignolo, W.D. (2012). Learning to unlearn: Decolonial reflections from Eurasia and the Americas. Columbus: The Ohio State University Press. 